\title{
Labor Market Policies and Outcomes in the Enlarged EU ${ }^{1}$
}

\author{
January 2009 \\ Forthcoming: Journal of Common Market Studies (2010: June)
}

\begin{abstract}
We document and compare labor market institutions, policies and outcomes in the EU member countries, for the period between 1999 and 2006. Higher employment rates are in general positively associated with measures of policy generosity, especially with the use of Active Labor Market Policies, and negatively with institutions and policies which induce rigidity in the labor market. We also find evidence that the relation between ALMP and employment levels is non-monotonic and that it is conditional on the informal institutions prevailing in different countries.
\end{abstract}

JEL Classification: J08, J38, J68.

Keywords: Labor market policy. Employment rate. European social models.

\section{Introduction}

The performance of labor markets has been at the center of many analyses and debates on the European economies. In the Eighties, the concept of "eurosclerosis" was often used to refer to the combination of slow growth, low employment creation and rigid labor markets which then characterized many "old" European countries. The functioning of labor markets has been a constant preoccupation of European policy makers, and it is

${ }^{1}$ Both authors: Università di Bologna and IzA.

We thank two anonymous referees and, for helpful comments on a previous version, Giorgio Bellettini, Andrea Ichino, Hartmut Lehmann, Anzelika Zaiceva and other participants to seminars at the Università di Bologna, Charles University (Prague, CZ) and London School of Economics (UK). This paper is a substantially revised version of: R. Rovelli and R.L. Bruno, "Labor Market Policies, Institutions and Employment Rates in the EU-27", IZA DP 3502, May 2008. 
also at the heart of the Lisbon strategy (which the European Council adopted in March 2000) and of its reappraisal in 2005. One main objective of that strategy was to raise the employment rate "as close as possible to $70 \%$ by 2010 " in all the EU member states - a goal that all the EU-15 members, but those who had already achieved it in 2000, were likely to miss even before the current crisis.

While well functioning labor markets are a key ingredient to a successful economic performance, labor market institutions also lie at the heart of the social models that so peculiarly characterize many EU members. ${ }^{2}$ Social policies clearly matter to the EU citizens, and citizens often outspokenly support their own country's labor market and social policies. In a recent Eurobarometer Survey on "European social reality" (2007), $51 \%$ of European Union citizens declared their satisfaction with the quality of the social welfare system in their own country. ${ }^{3}$

However, shared values and common objectives do not necessarily imply that policy competences should by allocated at the EU level and require EU legislative action. In fact, and in accord with the principle of subsidiarity, most competences in the field of social and labor market policies are left with individual member states. Thus, institutional pressure to adopt uniform labor markets and social policies within the EU is quite low, and the observed cross-country differences are likely to persist for a long time, unless member states spontaneously choose to learn from the best practice of others and thus to converge, possibly towards a single common model.

In this paper we characterize the main cross-country differences in labor market policies across EU member states, and relate various measures and policy indicators to indicators of labor market outcomes. The focus of our work is a comparative analysis of how employment rates in each country are related to indicators of labor market institutions and policies, and in particular to expenditures on Labor Market Programs (LMP).

The paper is organized as follows. In Section I we review the literature on the links between labor market institutions, policies and outcomes. In Section II we motivate our empirical analysis and discuss our results, subjecting them to a number of robustness checks. In a final section we offer some concluding remarks. A short Appendix describes the data and presents some additional results.

${ }^{2}$ For a concise characterization of the differences within EU labor market and social models, see Rovelli (2008).

3 The specific question asked was whether the welfare system in their country "provides wide enough coverage" (Eurobarometer Survey, 2007, p.76). Countries were respondents expressed the least support for their welfare systems were Bulgaria (2\%), Portugal $(5 \%)$, Latvia $(6 \%)$, Romania $(7 \%)$ and Greece $(8 \%)$. In general, the survey observes that "people's propensity to feel that their country's social welfare system could serve as a model for other countries is strongly related to whether they feel it provides enough coverage." (id., p.77). 


\section{Institutions, Policies and Outcomes: A Review}

The diversity within European countries of labor markets institutions and policies on the one hand and of outcomes on the other has been documented and analyzed in several papers and with different approaches. While some analyses also introduce cyclical factors and the role of adverse economic shocks in raising unemployment levels, most explanations focus on the roles of institutions and policies, and then additionally on their interactions with adverse shocks.

In one of the most cited comparative papers on the subject, Nickell (1997) studies the evolution of unemployment rates in 20 OECD countries, of which 15 in Europe, in 19831994. He finds that in general high unemployment is associated with welfare systems that do not put pressure on the unemployed to search for and accept work offers, with no coordination in wage bargaining and also with high taxes on labor and with poor educational standards at the bottom end of the market. Interestingly, strict employment protection, the degree of unionization and the generosity of benefits per se do not seem to affect unemployment. This result suggests that it is really the pressure to accept job offers - which may or may not be associated with the supply of unemployment benefits - that has an impact on the diversity of unemployment rates.

Somewhat in the same vein, Blanchard and Wolfers (2000) study the evolution of unemployment in 15 European countries over the 1960-1994 period. They also take into account the role of adverse and persistent macroeconomic shocks, caused by changes in oil prices, productivity and monetary and fiscal policies. By themselves, these shocks are not sufficient to explain either the persistence of high unemployment or the differences in cross-country unemployment rates. It is really the interactions of shocks and institutions (such as replacement rates, the duration of unemployment benefits, the level of employment protection laws - EPL -, the tax wedge, and also union contract coverage and density) that lead to a larger effect of shocks on unemployment. On the other hand other institutions, such as active labor market policies (ALMP) and more coordination in wage bargaining, have the opposite effects - that is, they dampen the effects of shocks on labor market outcomes.

Bassanini and Duval (2006) reappraise the same set of hypotheses, using a more recent and wider data set of 21 OECD countries over the period 1982-2003. They report that "high and long-lasting unemployment benefits, high tax wedges and stringent anticompetitive product market regulation are found to increase aggregate unemployment", and also to decrease labor market participation, particularly for groups of individuals located at the margins of the labor market. "By contrast, highly centralized and/or coordinated wage bargaining systems are estimated to reduce unemployment." In general, "changes in policies and institutions appear to explain 
almost two thirds of non-cyclical unemployment changes over the past two decades." According to Bassanini and Duval, the effects of different institutions and policies is quite large: "On average, ... a 10 percentage point reduction in the tax wedge, a 10 percentage point reduction of unemployment benefits and/or a decline in product market regulation by two standard deviations would be associated with a drop in the unemployment rate by about $2.8,1.2$ and 0.7 percentage points, respectively". In addition, they also document relevant interactions between policies and institutions, and observe that "the impact of generous unemployment benefits on unemployment appears to be mitigated by high public spending on ALMPs, perhaps because high spending on ALMPs is often accompanied with a strong emphasis on 'activation'", and also that "structural reforms appear to have mutually reinforcing effects: the impact of a given policy reform is greater the more employment-friendly the overall policy and institutional framework".

Contributions from political scientists and sociologists often adopt a different conceptual setup and a different format for the analysis, but their overall conclusions are not radically different from the economists'. For instance Bradley and Stephens (2007) appear to share many conclusions reached by Bassanini and Duval (2006); however they interpret their findings in relation to a wider debate between the neoliberal and institutional approaches. In their study, Bradley and Stephens also focus on the effects of policies and institutions on employment levels, in relation to 17 advanced industrial countries from 1974 to 1999 . They assume Denmark and the United States as two opposite benchmarks, representing "alternative paths to high employment". The contrast arises from the fact that "whereas the neoliberal policy prescriptions are best represented by the United States, Denmark best represents the policy package suggested by our analysis: very low social security taxes, modest EPL, strong ALMP effort, high levels of wage coordination and neocorporatism, and high short-term unemployment replacement rates" (Bradley and Stephens, 2007). They also acknowledge that in reality the two views share at least some common middle ground, for which they indeed find supportive evidence. More precisely they confirm the "neoliberal view" that high social security taxes, high level and long duration of unemployment benefits ${ }^{4}$ and strict EPL tend to reduce employment rates. However, on all of these points, the neoliberals and institutionalists share the same view. On the other hand several other neoliberal hypotheses found no support in their analysis: "Consistent with the institutionalist view and contrary to the neoliberal view, we found that neocorporatism, short-term unemployment replacement rates, and ALMP were

\footnotetext{
${ }^{4}$ On unemployment benefits, Howell, Baker, Glyn and Schmitt $(2007, \mathrm{p} .40)$ suggest instead that the positive correlation often observed between unemployment rates and gross benefit replacement ratios should be interpreted as causality running from the former to the latter.
} 
strongly related to employment levels, and total taxes were not related to employment levels"(id.).

Hence they end up finding broad confirmation for the institutionalist hypothesis, with two minor exceptions: "the hypotheses derived from institutionalist work that we did not find support for were ones in which they shared a common prediction with neoliberal economics. We found that union density had no effect when bargaining arrangements were controlled for and that wage dispersion had no effect" (id, p.1504).

Following a different sociological approach, Hicks and Kenworthy (2003) reappraise the analysis of Esping-Andersen (1990), who had identified three dimensions of the welfare states in the developed countries. On the basis of a principal component analysis, Hicks and Kenworthy (2003) suggest that it is convenient to summarize the varieties of welfare states along two dimensions, that of 'progressive liberalism' and of 'traditional conservatism'. At the one extreme of the first dimension they place respectively Denmark, Norway and Sweden (for progressive liberalism) and Austria, Belgium, France, Germany and Italy (for traditional conservatism). Interestingly, the US and Australia tend to be placed towards the opposite extremes of both dimensions ( $p$. 33). They then exploit both dimensions to explain employment performance ${ }^{5}$ between countries through an OLS regression, and find that, while progressive liberalism has no adverse impact on employment performance, traditional conservatism does have such a negative impact, which the authors attribute to the negative effect of "statist policies in more patriarchal, dirigiste, and Catholic welfare states" (p. 53). However, their method of analysis does not allow to single out the employment effects due to each policy measure or institution. This need not be interpreted as a shortcoming, if one maintains that the effect of many policies on the employment level can be either positive or negative, depending on the overall policy context, and that policy complementarities are quite common.

Boeri (2002), following Ferrera (1998), suggests an altogether different reappraisal of the Esping-Andersen "varieties". According to Boeri, four models of social policy were prevailing in the EU at the end of the $20^{\text {th }}$ century: the Nordic, Continental, Anglo Saxon and Mediterranean models. While in abstract one could think that all social models want to pursue to some extent three main tasks (to reduce poverty and income inequalities, to insure against labor market risks, and to increase the incentives and rewards from labor market participation) he argues that the latter task is crucial for developed countries in the context of contemporary, global challenges. Sapir (2006), following along similar lines of reasoning, evaluates the performance of the four models according

\footnotetext{
${ }^{5}$ They also analyze the impact of these dimensions on 'income redistribution' and 'gender equality in the labor market'.
} 
to the third criterion, that is how they stimulate labor market participation. He observes that the performance of the four models can be usefully compared "with a typology based on two criteria: efficiency and equity. A model will be considered efficient if it provides sufficient incentives to work and, therefore, if it generates relatively high employment rates. It will be deemed equitable if it keeps the risk of poverty relatively low." In his analysis, Nordic countries score well on both criteria, while continental countries provide equity (low poverty) at the price of low efficiency (low employment levels). Quite the opposite for Anglo-Saxon countries: they score well for efficiency but not for equity. Finally, Mediterranean countries score badly on both accounts.

Diverse as they may be, these analyses have a lot in common: they all suggest that there is a set of policies which, if properly enacted, contribute to increase the opportunities and rewards from labor market participation, while at the same time providing adequate or possibly generous insurance against labor market risks. Such policies seem to have found a more successful implementation in those countries, which fall within the boundaries of Sapir's "Nordic" model or of Hicks and Kenworthy's "progressive liberalism". And this conclusion is broadly coherent, at least prima facie, with the analyses of Nickell (1997) and of Blanchard and Wolfers (2000).

There is also a widespread agreement on the existence of a negative relation between the strictness of EPL and higher unemployment or lower employment levels: "most of the individual country studies demonstrate that regulations promoting job security ... on net reduce employment" (Heckman and Pagés, 2003).

Nevertheless, this leaves still ample room for more specific debates. In particular, as Dar and Tzanattos (1999) observe: "there are polar positions on the effectiveness of active labor market programs. On one hand, proponents of these programs argue that active labor market programs are necessary and useful, short only of a panacea for reducing unemployment and protecting workers. Opponents of the programs tend to summarily dismiss these programs as a waste of public money with high opportunity costs to other social programs and labor market efficiency as a whole."

And on the same point, Betcherman, Olivas and Dart (2004) observe that "some ALMPs do have positive impacts, with favorable cost-benefit ratios. However, in many cases, programs have not improved the future employment prospects of participants and, when they have, they have not always done so in a cost-effective manner. [...] Employment services are generally the most cost-effective intervention [...] and, compared to other ALMPs, [...] are inexpensive. Training programs for the unemployed can also have positive impacts on employment [...]. These programs are most effective when they are workplace-based." 
In the empirical analysis that follows, we shall also mainly focus on modeling employment rates, as it is done in most of the cited papers. In particular, we expect to find that employment rates are positively related to the adoption of Active LMP, although the size of the observed correlations and the cost-effectiveness of such programs may well vary according to the type of program, to the cyclical conditions prevailing at each time and to the degree of "employment-friendliness" provided by other relevant policies and institutions adopted in each country.

\section{Employment Rates in the Enlarged EU: an Empirical Analysis}

In this section we present our empirical analysis. Section II.1 compares labor market institutions, policies and outcomes in the EU-27. In section II.2 we motivate and discuss several regression models for the employment rates, and in section II.3 we provide several robustness checks.

\section{II.1 A first look at policies and outcomes}

In Table 1 and 2 we report summary statistics for labor market expenditures, institutional rigidities and labor market outcomes, respectively. Data cover all the EU member countries for which they are available, between 1999 and 2006. Using data for the previous years would have implied to concentrate only on the EU-15 members, thus largely replicating the studies reviewed in Section I. On the contrary, one of our main points of interest is to determine whether and to what extent the conclusions of these studies still apply to the enlarged EU. In the Tables, we only show figures for the beginning and end of the period.

\section{[Insert Table 1]}

The first six columns of Table 1 allow a cross-country comparison of expenditures on LMP as a ratio of GDP. We distinguish between expenditures on Active LMP in columns 1 and 2 (programmes 2 to 7, according to the Eurostat classification ${ }^{6}$ ), Passive LMP (8-9) in columns 3 and 4 and Total LMP (1-9) in columns 5 and 6 . Denmark and the other Nordic countries (Sweden and Finland, and also the Netherlands) clearly stand out in terms of policy generosity. At the other extreme, a few countries spend less than half the EU average of $2 \%$ of GDP in Total LMP, namely all the new members states (those that entered the EU since 2004) with the exception of Poland, and also Greece and the

\footnotetext{
${ }^{6}$ See the Appendix for a description of the dataset used.
} 
UK. ${ }^{7}$ Countries that engage in Active programmes also devote considerable resources to Passive policies (unemployment benefits and early retirement schemes): in 2006 the cross-country correlation between the two types of expenditures was $93 \%$.

The rigidity of employment index ${ }^{8}$ also varies considerably across countries (columns 7 and 8). Rigidity is lowest in Belgium, Czech Republic, Denmark and UK and highest both in some "old" EU members (Spain, France, Greece, Italy and Portugal) and some of the new ones (Estonia, Latvia, Lithuania and Romania). The tax wedge is less variable across countries(columns 9 and 10), whereas union density appears high especially in Denmark, Finland and Sweden (columns 11 and 12). ${ }^{9}$ Short term replacement rates ${ }^{10}$ range from a minimum of $25 \%$ in Lithuania to $78 \%$ in Portugal and Sweden (columns 13 and 14). In general, all these measures do not vary much in the period considered.

[Insert Table 2]

[Insert Figure 1]

In Table 2 we report the rates of employment, unemployment and participation in 1999 and 2006, as well as their period change. Employment rates in particular have evolved quite differently across the EU-27 economies. This is also shown in more detail in Figure 1. Employment rates have been high and in general constant in many countries, and especially Austria, Denmark, Netherlands, Sweden and UK have already reached the socalled "Lisbon objective" of 70\%. Spain and Bulgaria show the largest increases. On the other hand, employment levels are still low in Bulgaria, Hungary, Italy, Malta, Poland, Romania and Slovakia. Poland and Romania are especially worrying, since employment levels have been on average decreasing significantly during the period.

Following Sapir (2006), we also compare employment rates and poverty levels across countries and periods. This comparison can be taken as a synthetic representation of labor market efficiency versus equity. Figure 2 documents this evolution, between 1999 and 2006. For the EU-15, employment rates have on average increased, while poverty rates have remained constant. We may use the EU-15 averages for 2006 (vertical and

7 It has been observed that the composition of social expenditures in the UK is different from that of other countries, as more social expenditures take the form of non-labor related expenditures. However this difference does not affect our regression results.

${ }^{8}$ Available for 2003 and 2006, see the Appendix. The studies referred to in the literature review have used the EPL1 and EPL2 (employment protection legislation) indexes from the OECD. However this indicator is missing for most new member states. In any case, for those countries for which both measures are available, the correlation between EPL and the Rigidity index included in Table 1 is quite high.

${ }^{9}$ Checchi and Lucifora (2002) study the evolution and determinants of union density rates across 14 EU countries.

10 The literature distinguishes also between the effects of short and long rates. See for example Nickell, Nunziata and Ochel (2005). 
horizontal lines) to roughly divide the graph in four parts, where we expect to find (following the initial suggestion from Sapir) the Mediterranean and Anglo-Saxon countries in the top left and right, and the Continental and Nordic countries in the bottom left and right, respectively. Figure 2 allows us to track also the changes occurred between 1999 and 2006. We observe three main "facts":

- Several NMS initially are positioned in the "Mediterranean" block, although those with higher income per capita (Czech Republic and Slovenia, and also Slovakia) belong with the "Continental" block;

- Most countries move to the right (higher employment rates), while poverty rates remain largely constant, ${ }^{11}$ with a few exceptions. This movement makes the "Mediterranean" and the "Anglo-Saxon" blocks closer to each other, and the same goes for the "Continental" and "Nordic" blocks;

- Looking at individual countries, it is notable that Poland and Romania are the only two countries that clearly move in both the "wrong" directions, and further away from the EU-15 average.

\section{[Insert Figure 2]}

As these data show, it is really the cross-country heterogeneity of employment rates that characterizes the data, together with a tendency at clustering around the higher employment levels. For this reason, and also since the potentially explanatory variables are quite different across countries and much less across time (see Table 1), we shall focus on modeling employment levels in the regression analysis that follows. ${ }^{12}$

\section{2 Modeling employment rates}

The purpose of the regression analysis is to investigate the relationship between the employment rate as a dependent variable and labor market institutions and policies as independent variables. Nickell (1997) and Blanchard and Wolfers (2000), among others, have found that the following variables were relevant to explain labor market outcomes: rigidity of employment, ${ }^{13}$ replacement rates (measured as the ratio of benefits to wages), duration of unemployment benefits, expenditure on active labor market

11 As the main purpose of this graph is to compare "outcomes" in two different dimensions, we plot on the vertical axis the poverty rate after taxes and subsidies.

12 On the other hand, since unemployment rates are considerably more variable across time than employment rates, they are more naturally amenable to the kind of analysis developed by Blanchard and Wolfers (2000) and also by Nickell, Nunziata and Ochel (2005).

13 See footnote 8. As a robustness check, we also use EPL2 as a regressor, for the subset of countries for which it is available. Results are reported in Table A3 and discussed in section 3.3, but they do not change appreciably from those in Table 3. 
policies, union density, coverage of union contracts, coordination of wage bargaining and the tax wedge. We have collected these variables for the largest number of EU countries and the longest time span available. In the end we restricted ourselves to the period 1999-2006 and to 23 countries, for some of which we only have observations for the second half of the sample. We also decided not to use union coverage and coordination of wage bargaining (see the Appendix for more details on data availability). Following the procedure outlined by Nickell (1997), we average the observations in two sub-periods (1999-2002; 2003-2006). We thus obtain a "short" two-period panel. We also include in the regressions the change in inflation rates between the beginning and the end of each sub-period, measured at the country level, and a time dummy for the second period, to control for the difference in business cycles and common macro shocks, respectively.

To obtain a first benchmark, we follow the literature on the varieties of social models and labor market policies and regress employment rates on four geographical dummies, representing the four geographic groups observed by Boeri (2002) and Sapir (2006), plus one dummy for the New Member States (NMS). Results are shown in Table 3, column 1, and also plotted in Figure 3. The geographical dummies are basically all significant and the goodness of fit is apparently high (adjusted $R^{2}$ equal to $52 \%$ ). However a closer examination of Figure 3 shows that this result is really deceptive, as the observations for many countries in the different groups overlap with each other on the vertical scale.

\section{[Insert Table 3]}

[Insert Figures 3 and 4]

In column 2 we introduce a set of partially "New Geographical Dummies"14. They all have significant coefficients and the adjusted $\mathrm{R}^{2}$ increase to $58 \%$. But also in this case there is a relevant overlap of the observations from the different groups (see Figure 4).

From column 3 onwards we introduce additional regressors to measure labor market institutions and policies. In particular we use two alternative specifications of ALMP. In one case we simply scale policy expenditures by GDP (column 3); in the other we further divide it by the unemployment rate, for the reason discussed in Nickell (1997) (column 4). In both cases ALMP are non significant. Instead, the rigidity index and the replacement rates are quite significant and correctly ${ }^{15}$ signed. Only one geographical dummy loses significance, FTR ("Fast Transition"), whereas the dummies for CTE ("Continental Enlarged", which also includes some NMS), MEE ( "Mediterranean

\footnotetext{
${ }^{14}$ See Table A1 in the Appendix for a definition of these dummies (Nord, FtR, PoRo, CTE, MeE).

${ }^{15}$ According to the institutionalist view.
} 
Enlarged", which includes Cyprus and Malta) and PoRo (Poland and Romania, the two "mis-behaving" countries noted in Figure 2) retain their significance. If we drop the geographical dummies entirely, the pattern of significant institutions changes again (columns 5 and 6). Focusing on column 6, where we use the "Nickell" variable ([ALMP/GNP]/Unemployment), we observe a strong positive coefficient for this variable. Also the short term replacement rate and union density have a significant positive effect, and the tax wedge a negative one.

However, even after dropping the geographical dummies, it is still necessary to account for country effects. We do this in the remaining columns 7 to 10 , where we use a Random Effect (RE) model. This is a least square model corrected for the fact that the two successive observations for each country cannot be treated as independent random draws (see Nickell, 1997). Moreover, as we also include some time-invariant regressors (see Appendix), we cannot use a Fixed Effect model. The RE model allows us to account for part of the unobserved (random) heterogeneity, ${ }^{16}$ and thus should give improved coefficient estimates. In column 7 we show the RE estimation of the same equation as in column $6 .{ }^{17}$ The tax wedge and the replacement rates are no longer significant, but the union density and ALMP retain their significance and a similar magnitude. Similarly, in column 8 we show the RE estimation of the same equation as in column 5: again we find that ALMP is non significant, when it is only deflated by GDP. We suspect that this may be related to the fact that ALMP have different effects, depending on a country's informal institutions and culture. Thus in columns 9 and 10 we additionally interact ALMP/GNP with a dummy variable, respectively "Religion" (equal to 1 if more than $50 \%$ of the population has a Catholic or Orthodox affiliation) and "negative work ethic", (defined as the percentage in a representative sample of the population in each country of those who agree with the statement that "People should not have to work if they do

16 If there is no correlation between observed country characteristics included in the regression (labor market institutions, change in inflation) and unobserved country effects (time-invariant), both fixed and random effect techniques provide consistent estimates of the coefficients in the equation. However, the random effect estimation is more efficient, i.e. the standard errors of the estimators are lower. In fact the within-fixed effects 'throw away' variability, either by differencing (in the case of two observations across time) or by computing the distance from the mean (in the case of more than two). The random effect estimation, on the other hand, simply accounts for the fact that the errors for paired observations in the panel are correlated with one another. Hence, unpaired observations need to be weighted differently, in order to account for heteroskedasticity. However this is only a theoretical possibility. We might suspect that there is correlation between observed country characteristics and unobserved country effects and, and that case, we should use FE.

17 Fialova and Schneider (2008) also report results similar to those of column 7, in reference to a broadly overlapping sample of countries. 
not want to"). ${ }^{18}$ Column 9 shows that the relation between ALMP and employment rates is now positive and significant for the non Catholic nor Orthodox countries (coefficient = +5.6 ) while for Catholic or Orthodox countries it is negative (the net effect is given by: $5.6-8.7=-3.1$ ). Column 10 shows a similar interaction effect in countries where a high number of citizens support a negative work ethic. The interpretation of the regression coefficients in this column is as follows: since the ratio of the absolute value of the two coefficients (ALMP and ALPM $\times$ Culture) is equal to $38 \%=16.2 / 42.6$, this implies that, in countries where the percentage of respondents who support a "low" work ethics is below $38 \%,{ }^{19}$ the relation between ALMP and employment rates is positive. Vice-versa, for countries where the percentage of respondents who support a low work ethic is above $38 \%$, the relation is negative. This result is in line with the idea that a social model based on a more intensive recourse to active policies would be well functioning in the Scandinavian countries (but also in the UK, Slovenia and Slovakia, for example). Figure 5 shows the fitted-actual graph for the RE model presented in column 10. The lining up of actual values along the 45 degrees line can now be favorably compared with those in Figures 3 and 4.

As a notice of caution, however, we must also report that if we use either of the cultural interaction variables (religion; work ethic) in regressions where ALMP is measured "à la Nickell" (that is, deflated by unemployment rates), then we do not obtain significant results. We interpret this result as suggesting that the [ALMP/GDP]/Unemployment ratio is a better and timelier measure of the counter-cyclical impact of labor market policies; whereas using the simple ALMP/GDP ratio is a better indicator of a "structural" policy stance, whose effectiveness is really conditioned by the overall framework of each country's formal and informal institutions.

[Insert Figure 5]

\section{II.3 Robustness Checks}

In this section we present some additional regression results, as a robustness check for the results in Table 3. First, we experiment with the use of alternative measures of labor market expenditures. In Table 3 we used expenditures on ALMP according to the Eurostat classification. In Table 4 we reproduce (for ease of comparability) as column 1 , 4, 7 the results of columns 7, 9, 10 of Table 3 . In columns 2, 5, 8 instead we use

\footnotetext{
18 This variable is obtained from the World Value Survey, and takes higher values as the proportion of those who agree with this statement increases. See http://www.worldvaluessurvey.org/

19 These countries are: Netherlands, United Kingdom, Slovakia, Slovenia, Sweden, Denmark, Portugal, Hungary, Austria and Germany.
} 
expenditure on passive LMP (PLMP); in columns 3, 6, 9 Total LMP (TLMP). ${ }^{20}$ In general there are no major differences in the sign and significance of the coefficients of LMP using alternative measures, although (as it would be expected in the case of a "causal" effect running from policies to employment rates) the highest coefficient can always be associated with active policies.

\section{[Insert Table 4 and 5]}

Second, in Table 5 we modify the dependent variable, using participation rates instead of employment rates. We expect to get a weaker relation between LMP and the participation rate, as the latter includes the dynamics of both unemployment and employment rates. LMP should enhance the overall participation rate, however they might impinge with a negative sign on unemployment and a positive sign on employment, and this is likely to reduce the estimated impact on the overall participation rate. Results line up with our expectations, and confirm those of Table 4, as the magnitude and statistical significance of the coefficients in Table 5 are reduced, as expected, but retain the same signs.

Third, in Table A2 of the Appendix we modify the sample in order to account for the largest available number of countries. Including $25 \mathrm{EU}$ countries in the regression allows us to exploit 41 observations. The statistical significance of all the coefficients on LMP is even stronger. We also confirm the evidence that LMP and employment levels are non-monotonically related, by accounting for cross-country differences in "culture" (religion and work ethic). However in these regressions we are unable to include measures for union density and for the short term replacement rate, as these data are unavailable for the added countries.

Finally, in Table A3 of the Appendix we introduce a measure of the strictness of "Employment Protection Laws" (EPL, source: OECD) in place of the "Rigidity of Employment Index" (World Bank). In addition, we also include an indicator of the strictness of "Product Market Regulation" (source: OECD). No major differences are detected on the impact of LMP on the dependent variable. The index of product market regulation is negatively associated with the employment level and EPL is insignificant. However in this case the number of countries is only 18 and the sample size drops to 31 observations, impinging both on the efficiency of the estimators and the available degrees of freedom.

\section{Conclusions}

\footnotetext{
${ }^{20}$ See the Appendix for the relation between policy types and the Eurostat classification.
} 
In this paper we have explored the relations between employment rates and several indicators of labor market institutions and policies. Our study is focused on the EU and it is based on macro variables that cover between 23 and 25 countries. Using the same or a comparable set of indicators as in Nickell (1997) and Blanchard and Wolfers (2000), we have observed that expenditures on labor market programmes, and especially on active programmes, are significantly positively related to employment levels. Other variables often used in previous research are found to have much less significant and stable effects, except possibly for union density, which in some specifications seems also to be positively correlated to employment levels; on the other hand this variable is significantly higher in the three Scandinavian countries, and thus may be really proxying for the specific features of their labor market institutions.

We have also confirmed that the relationship between ALMP and employment rates is non-monotonic. We interpret this to imply that ALMP may have a positive impact on employment especially in those countries where informal institutions support a strong "pro-work", and possibly a more individualistic attitude; vice-versa, in countries where these attitudes are not widely shared there is no indication that ALMP are positively related to employment rates. Similarly, we have found that the relation between ALMP and employment rates is negative in countries with a prevailing Catholic or Orthodox affiliation, while it is significantly positive in the other countries. We suggest that these results may be interpreted in the light of the previous findings of Bassanini and Duval (2006), that "structural reforms appear to have mutually reinforcing effects: the impact of a given policy reform is greater the more employment-friendly the overall policy and institutional framework". Our results suggest that the notion of an institutional framework should be enlarged, to include the role of informal institutions.

As a note of caution, we acknowledge that the aggregate nature of our analysis limits the confidence in the robustness and in the interpretation of our results. However, and for the same reason, these results contribute to weaken the conclusions of previous studies sharing the same methodology, on the role of specific labor market polices and institutions, such as measures of employment rigidity, tax wedge and union density. We suggest that these variables may really be acting as confounding factors for other informal institutions or country characteristics.

Also, we have tentatively suggested that analyses based on the "macro" framework adopted by Nickell (1997) and others, and those which follow a more "institutionalist" approach, focused on the variety of labor market models, can be meaningfully integrated in the same empirical framework. When this is done, informal institutions more than simple "geography" appear to embody the relevant discriminant factors to account for the observed differences in the performance of labor markets. 


\section{References}

Bassanini, A. and Duval, R. (2006) "Employment Patterns in OECD Countries: Reassessing the Role of Policies and Institutions". OECD Economics Department W.P. 486.

Betcherman, G.; Olivas, K. and Dar, A. (2004), "Impacts of Active Labor Market Programs: New Evidence from Evaluations with Particular Attention to Developing and Transition Countries". World Bank - Social Protection D.P. 04.02

Blanchard, O. and Wolfers, J. (2000), "The Role of Shocks and Institutions in the Rise of European Unemployment: the Aggregate Evidence". The Economic Journal, 110, C1-C33.

Boeri, T. (2002), "Let Social Policy Models Compete and Europe Will Win". Paper presented at a Conference hosted by the Kennedy School of Government, Harvard University, 11-12 April 2002.

Bradley, D.H. and Stephens, J.D. (2007), "Employment Performance in OECD Countries. A test of Neoliberal and Institutionalist Hypotheses". Comparative Political Studies, 40(12), 1486-1510.

Checchi, D. and Lucifora, C. (2002), "Unions and Labour Market Institutions in Europe", Economic Policy pp. 363-408.

Conway, P.; Janod, V. and Nicoletti, G. (2005), "Product Market Regulation in OECD Countries, 1998 to 2003", OECD Economics Department W.P., No 419.

Dar, A. and Tzannatos, Z. (1999), "Active labor market programs: a review of the evidence from evaluations". World Bank - Social Protection D.P. 99.01.

Esping-Andersen, G. (1990), "The Three Worlds of Welfare Capitalism", Princeton, NJ, Princeton University Press.

Eurobarometer survey (2007), "European social reality". Special Eurobarometer 273, February. http://ec.europa.eu/public opinion/archives/ebs/ebs 273 en.pdf

Ferrera, M. (1998), "The Four 'Social Europes': Between Universalism and Selectivity". In Rhodes, M.; and Meny. Y. (eds.) The future of European welfare: a new social contract?, Basingstoke: Macmillan.

Fialova, K. and Schneider, O. (2008), "Labour Market Institutions and their Effect on Labour Market Performance in the New EU Member Countries". CESIFO W.P. no 2421, October. 
Heckman, J. and Pages, C. (2003), "Law and Employment: Lessons from Latin America and the Caribbean". NBER W.P. no. 10129.

Hicks, A. and Kenworthy, L. (2003) "Varieties of Welfare Capitalism". Socio-Economic Review, 1, 27-61.

Howell, D.R.; Baker, D.; Glyn, A. and Schmitt, J. (2007) "Are Protective Labor Market Institutions at the Root of Unemployment? A Critical Review of the Evidence". Capitalism and Society, The Berkeley Electronic Press, 2(1), Article 1.

Nicoletti, G. and Scarpetta, S. (2005), "Regulation and economic performance: product market reforms and productivity in the OECD". OECD Economics Department W.P. 460.

Nickell, S. (1997), "Unemployment and Labor Market Rigidities: Europe versus North America", The Journal of Economic Perspectives, 11(3), pp 55-74.

Nickell, S.; Nunziata, L. and Ochel, W. (2005), "Unemployment in the OECD since the 1960s: What Do We Know?", The Economic Journal, 115, pp 1-27.

Rovelli, R. (2008), "One Market, How many Social Models? Policy and Performance Indicators in the EU", in European Integration at the Crossroads, Luboš T., Plechanovová, B. and Schneider,O. (eds.), Universitas Carolina Facultas Iuridica, Prague, pp. 77-115.

Sapir, A. (2006), "Globalization and the Reform of European Social Models". Journal of Common Market Studies, 44 (2), pp. 369-390.

Visser, J. (2006), "Union membership statistics in 24 countries", Monthly Labour Review, pp. 38-49. 


\section{Appendix: The Data}

Definitions and sources of the variables used in the regression analysis are provided in Table A1, and the most relevant data are tabulated in Tables 1 and 2 in the text. All variables have been collected, when available, on a yearly basis from 1999 to 2006.

In particular we have used data from the following sources:

* Eurostat (http://epp.eurostat.ec.europa.eu): National Accounts and Public Finance data. Growth rates. Structural indicators on innovation and research, education, employment, unemployment, inequality and social cohesion, market integration and business demography. Expenditure and participants to labor market programmes.

We report below the Eurostat classification for Expenditures on LMP:

\begin{tabular}{|l|l|}
\hline \multicolumn{1}{|c|}{ Active: } & \multicolumn{1}{c|}{ Passive: } \\
\hline 1. labor market services & 8. out-of-work income maintenance and support \\
\hline 2. training & 9. early retirement. \\
\hline 3. job rotation and job sharing & \\
\hline 4. employment incentives & \\
\hline 5. integration of the disabled & \\
\hline 6. direct job creation & \\
\hline 7. start-up incentives. & \\
\hline
\end{tabular}

* OECD (http://stats.oecd.org/WBOS/Default.aspx): EPL and Product Market indicators.

* World Bank-Doing Business (http://www.doingbusiness.org/EconomyRankings/): Data on ease of employing workers.

* CIA World Factbook (https://www.cia.gov/library/publications/the-worldfactbook/index.html): Data on religions.

* World Values Survey (http://www.worldvaluessurvey.org/): Data on attitudes toward work (question 'c040': do you agree to the following statement "people should not work if they do not want to").

In order to build the sample used in the regressions, we have computed two 4-year averages, i.e. two data points (1999-2002; 2003-2006), to be used as a rather short two-period panel (see Nickell 1997). Some variables are available for all the countries and all the periods, other variables have missing values. Benefit duration and the union coordination are missing for both periods in 10 countries (Bulgaria, Cyprus, Estonia, Greece, Lithuania, Luxemburg, Latvia, Malta, Romania and Slovenia), labor market expenditures are missing for 11 countries in the 1999-2002 period (Bulgaria, Cyprus, Estonia, Hungary, Lithuania, Latvia, Malta, Poland, Romania, Slovenia and Slovakia), the index of the rigidity of employment is missing for both periods for Malta and Cyprus 
(Luxembourg is also missing, but we have used the average of the observations for Germany and Belgium ${ }^{21}$ ).

[insert Table A1]

When including all the eight labor market institutions used in the analyses of Nickell (1997) and Blanchard and Wolfers (2000), the overlapping non-missing observations for the two periods are 31 and the included countries are 18.

By including only labor market expenditures, rigidity employment index, tax wedge, union density and average replacement rate the overall number of observations increases to 39 in 23 countries (Malta, Cyprus, Bulgaria and Romania are missing). This is the sample which we have used for Tables 3,4 and 5.

If we additionally exclude union density and the replacement rate we obtain a sample with 41 observations, as Bulgaria and Romania can now be included. We do use this sample as a robustness check in Table A2. As it can be seen, the coefficients of the remaining included variables are not appreciably affected, and the role of LMP emerges even more strongly (see also the comment within the text).

[insert Table A2]

Finally, Table A3 includes Employment Protection Legislation (EPL2) from the OECD instead of the Rigidity Employment Index compiled by the World Bank and the Product market regulation Variable (OECD) that has been exploited by some papers, e.g. Nicoletti and Scarpetta (2005), Bassanini and Duval (2006). In this set of regressions the number of observation is 31 for 18 countries only. The main results on the significant impact of ALMP are unaffected. The product market regulation variable, if significant, shows a negative sign, as expected.

[Insert Table A3]

\footnotetext{
${ }^{21}$ Regressions results are not affected by this replacement.
} 
Table 1. Labor Market Expenditures and Institutional Rigidities, 1999 - 2006

\begin{tabular}{|c|c|c|c|c|c|c|c|c|c|c|c|c|c|c|c|}
\hline & \multirow[b]{2}{*}{ id } & \multicolumn{2}{|c|}{$\begin{array}{c}\text { Labor Market } \\
\text { Expenditures 2-7 }\end{array}$} & \multicolumn{2}{|c|}{$\begin{array}{c}\text { Labor Market } \\
\text { Expenditures 8-9 }\end{array}$} & \multicolumn{2}{|c|}{$\begin{array}{c}\text { Labor Market } \\
\text { Expenditures 1-9 }\end{array}$} & \multicolumn{2}{|c|}{$\begin{array}{l}\text { Rigidity of Employment } \\
\text { Index }\end{array}$} & \multicolumn{2}{|c|}{ Tax Wedge } & \multicolumn{2}{|c|}{ Union Density } & \multicolumn{2}{|c|}{ Replacement rate } \\
\hline & & 1999 & 2006 & 1999 & 2006 & 1999 & 2006 & 2003 & 2006 & 1999 & 2006 & 1999 & 2006 & 1999 & 2006 \\
\hline EU (15 countries) & eu15 & 0.34 & 0.52 & 1.37 & 1.25 & 1.71 & 1.99 & 41 & 42 & 38 & 40 & 28 & 36 & 57 & 57 \\
\hline Austria & at & 0.40 & 0.55 & 1.31 & 1.39 & 1.85 & 2.11 & 33 & 37 & 41 & 41 & 37 & 35 & 55 & 55 \\
\hline Belgium & be & 0.25 & 0.88 & 1.82 & 1.81 & 2.28 & 2.89 & 27 & 20 & 44 & 43 & 55 & 55 & 63 & 63 \\
\hline Bulgaria & bg & - & 0.39 & - & 0.18 & - & 0.63 & 46 & 47 & 37 & 31 & - & - & - & - \\
\hline Cyprus & cy & - & 0.07 & - & 0.66 & - & 0.76 & - & - & 23 & 24 & - & - & - & - \\
\hline Czech Republic & $\mathrm{cz}$ & 0.11 & 0.12 & 0.28 & 0.23 & 0.46 & 0.48 & 20 & 28 & 41 & 41 & 33 & 22 & 50 & 50 \\
\hline Germany & de & 1.07 & 0.62 & 2.12 & 2.10 & 3.19 & 2.99 & 44 & 44 & 40 & 40 & 26 & 23 & 61 & 61 \\
\hline Denmark & $\mathrm{dk}$ & 1.83 & 1.52 & 2.57 & 2.66 & 4.40 & 4.34 & 16 & 17 & 40 & 37 & 74 & 70 & 64 & 61 \\
\hline Estonia & ee & - & 0.04 & - & 0.07 & - & 0.13 & - & 58 & 40 & 34 & 20 & 11 & 50 & 50 \\
\hline Spain & es & 0.63 & 0.63 & 1.45 & 1.44 & 2.08 & 2.17 & 62 & 63 & 28 & 32 & 16 & 16 & 72 & 69 \\
\hline Finland & $\mathrm{fi}$ & 0.90 & 0.73 & 2.33 & 1.69 & 3.34 & 2.55 & 44 & 48 & 43 & 42 & 76 & 74 & 61 & 60 \\
\hline France & $\mathrm{fr}$ & 1.05 & 0.68 & 1.52 & 1.40 & 2.74 & 2.32 & 55 & 56 & 43 & 42 & 8 & 8 & 71 & 73 \\
\hline Greece & gr & 0.24 & 0.06 & 0.40 & 0.4 & 0.64 & 0.47 & 58 & 58 & 37 & 38 & 26 & 25 & 45 & 48 \\
\hline Hungary & hu & - & 0.19 & - & 0.36 & - & 0.64 & 33 & 34 & 43 & 39 & 33 & 17 & 47 & 43 \\
\hline Ireland & ie & 0.87 & 0.46 & 1.11 & 0.87 & 1.98 & 1.57 & 27 & 33 & 29 & 25 & 41 & 35 & 29 & 30 \\
\hline Italy & it & 0.53 & 0.44 & 0.67 & 0.80 & 1.20 & 1.27 & 53 & 54 & 44 & 43 & 36 & 34 & 52 & 54 \\
\hline Lithuania & It & - & 0.18 & - & 0.13 & - & 0.40 & 47 & 48 & 39 & 34 & 16 & 14 & 25 & 25 \\
\hline Luxembourg & lu & 0.08 & 0.39 & 0.50 & 0.59 & 0.58 & 1.04 & 44 & 44 & 30 & 30 & 13 & 13 & 61 & 61 \\
\hline Latvia & IV & - & 0.17 & - & 0.30 & - & 0.54 & 62 & 59 & 37 & 34 & 19 & 16 & 50 & 50 \\
\hline Malta & $\mathrm{mt}$ & - & 0.07 & - & 0.41 & - & 0.56 & - & - & 19 & 22 & - & - & - & - \\
\hline Netherlands & $\mathrm{nl}$ & 0.92 & 0.75 & 2.01 & 1.47 & 2.93 & 2.69 & 42 & 42 & 34 & 34 & 25 & 22 & 71 & 71 \\
\hline Poland & $\mathrm{pl}$ & - & 0.37 & - & 0.71 & - & 1.17 & 37 & 33 & 36 & 34 & 24 & 16 & 47 & 52 \\
\hline Portugal & pt & 0.31 & 0.45 & 0.81 & 1.27 & 1.23 & 1.85 & 56 & 51 & 27 & 29 & 23 & 23 & 78 & 78 \\
\hline Romania & ro & - & 0.10 & - & 0.28 & - & 0.42 & 65 & 51 & 48 & 42 & - & - & - & - \\
\hline Sweden & se & 1.95 & 1.13 & 1.64 & 0.96 & 3.59 & 2.28 & 42 & 43 & 49 & 45 & 81 & 78 & 78 & 77 \\
\hline Slovenia & si & - & 0.18 & - & 0.39 & - & 0.67 & 57 & 57 & 38 & 38 & 41 & 44 & 63 & 63 \\
\hline Slovakia & sk & - & 0.13 & - & 0.34 & - & 0.64 & 38 & 39 & 37 & 30 & 45 & 30 & 64 & 64 \\
\hline United Kingdom & uk & 0.09 & 0.04 & 0.36 & 0.19 & 0.45 & 0.60 & 13 & 14 & 25 & 26 & 30 & 29 & 45 & 45 \\
\hline
\end{tabular}

See Table A1 for source and definition of data on Labor Market Expenditures (Source Eurostat). All Expenditures reported as \% of GDP.

Expenditures 2-7: Active LMP; Expenditures 8-9: Passive LMP; Expenditures 1-9: Total LMP (includes also exp. in labor market services). Correlation between Active and Passive LMP: 93\%.

Expenditure data n.a.in the 1999-2002 for Bulgaria, Cyprus, Estonia, Hungary, Lithuania, Latvia, Malta, Poland, Romania, Slovenia and Slovakia. For Denmark we use 2004 data for 2006 , for Greece 2005 for 2006, for Czech Republic 2002 for 1999.

Replacement rate: net value of replacement benefits in the initial phase of unemployment relative to average wage, single with no children. We use 2001 data for 1999,2004 for 2006 (Source OECD). 
Table 2. Labor Market Outcomes, 1999 - 2006

\begin{tabular}{|c|c|c|c|c|c|c|c|c|c|c|}
\hline & \multirow[b]{2}{*}{ id } & \multicolumn{3}{|c|}{1999} & \multicolumn{3}{|c|}{2006} & \multicolumn{3}{|c|}{ Delta 2006 - 1999} \\
\hline & & Emp. & Unemp. & Part. & Emp. & Unemp. & Part. & Emp. & Unemp. & Part. \\
\hline EU (15 countries) & eu15 & 62.5 & 8.5 & 68.3 & 66.2 & 7.7 & 71.7 & 3.7 & -0.8 & 3.4 \\
\hline Austria & at & 68.6 & 3.9 & 71.4 & 70.2 & 4.8 & 73.7 & 1.6 & 0.9 & 2.4 \\
\hline Belgium & be & 59.3 & 8.5 & 64.8 & 61.0 & 8.3 & 66.5 & 1.7 & -0.2 & 1.7 \\
\hline Bulgaria & bg & 50.4 & 16.4 & 60.3 & 58.6 & 9.0 & 64.4 & 8.2 & -7.4 & 4.1 \\
\hline Cyprus & cy & 65.7 & 4.9 & 69.1 & 69.6 & 4.6 & 73.0 & 3.9 & -0.3 & 3.9 \\
\hline Czech Republic & $\mathrm{cz}$ & 65.6 & 8.6 & 71.8 & 65.3 & 7.2 & 70.4 & -0.3 & -1.4 & -1.4 \\
\hline Germany & de & 65.2 & 8.2 & 71.0 & 67.5 & 9.8 & 74.8 & 2.3 & 1.6 & 3.8 \\
\hline Denmark & $\mathrm{dk}$ & 76.0 & 5.2 & 80.2 & 77.4 & 3.9 & 80.5 & 1.4 & -1.3 & 0.4 \\
\hline Estonia & ee & 61.5 & 11.3 & 69.3 & 68.1 & 5.9 & 72.4 & 6.6 & -5.4 & 3.0 \\
\hline Spain & es & 53.8 & 12.5 & 61.5 & 64.8 & 8.5 & 70.8 & 11.0 & -4.0 & 9.3 \\
\hline Finland & $\mathrm{fi}$ & 66.4 & 10.2 & 73.9 & 69.3 & 7.7 & 75.1 & 2.9 & -2.5 & 1.1 \\
\hline France & $\mathrm{fr}$ & 60.9 & 10.4 & 68.0 & 63.8 & 9.2 & 70.3 & 2.9 & -1.2 & 2.3 \\
\hline Greece & gr & 55.9 & 12.0 & 63.5 & 61.0 & 8.9 & 67.0 & 5.1 & -3.1 & 3.4 \\
\hline Hungary & hu & 55.6 & 6.9 & 59.7 & 57.3 & 7.5 & 61.9 & 1.7 & 0.6 & 2.2 \\
\hline Ireland & ie & 63.3 & 5.7 & 67.1 & 68.6 & 4.5 & 71.8 & 5.3 & -1.2 & 4.7 \\
\hline Italy & it & 52.7 & 11.0 & 59.2 & 58.4 & 6.8 & 62.7 & 5.7 & -4.2 & 3.4 \\
\hline Lithuania & It & 61.7 & 13.7 & 71.5 & 63.6 & 5.6 & 67.4 & 1.9 & -8.1 & -4.1 \\
\hline Luxembourg & lu & 61.7 & 2.4 & 63.2 & 63.6 & 4.6 & 66.7 & 1.9 & 2.2 & 3.4 \\
\hline Latvia & Iv & 58.8 & 14.0 & 68.4 & 66.3 & 6.8 & 71.1 & 7.5 & -7.2 & 2.8 \\
\hline Malta & $\mathrm{mt}$ & 54.2 & 6.7 & 58.1 & 53.6 & 7.1 & 57.7 & -0.6 & 0.4 & -0.4 \\
\hline Netherlands & $\mathrm{nl}$ & 71.7 & 3.2 & 74.1 & 74.3 & 3.9 & 77.3 & 2.6 & 0.7 & 3.2 \\
\hline Poland & $\mathrm{pl}$ & 57.6 & 13.4 & 66.5 & 54.5 & 13.9 & 63.3 & -3.1 & 0.5 & -3.2 \\
\hline Portugal & $\mathrm{pt}$ & 67.4 & 4.5 & 70.6 & 67.9 & 7.8 & 73.6 & 0.5 & 3.3 & 3.1 \\
\hline Romania & ro & 63.2 & 7.1 & 68.0 & 58.8 & 7.3 & 63.4 & -4.4 & 0.2 & -4.6 \\
\hline Sweden & se & 71.7 & 6.7 & 76.8 & 73.1 & 7.0 & 78.6 & 1.4 & 0.3 & 1.8 \\
\hline Slovenia & si & 62.2 & 7.3 & 67.1 & 66.6 & 6.0 & 70.9 & 4.4 & -1.3 & 3.8 \\
\hline Slovakia & sk & 58.1 & 16.4 & 69.5 & 59.4 & 13.4 & 68.6 & 1.3 & -3.0 & -0.9 \\
\hline United Kingdom & uk & 71.0 & 5.9 & 75.5 & 71.6 & 5.4 & 75.7 & 0.6 & -0.5 & 0.2 \\
\hline
\end{tabular}

Source: Eurostat. Employment Rate = em011 (new SI code tsiem010), Unemployment Rate = em071 (new SI code tsiem110)

Participation Rate $=$ Employment rate $*[1 /(1-$ Unemployment rate) $]$. 
Table 3. Dependent Variable: Employment Rate

\begin{tabular}{|c|c|c|c|c|c|c|c|c|c|c|}
\hline & \multicolumn{6}{|c|}{ OLS Model } & \multicolumn{4}{|c|}{ Random Effect Model } \\
\hline & (1) & (2) & (3) & (4) & (5) & (6) & (7) & (8) & (9) & (10) \\
\hline & & & [ALMP/GDP] & $\frac{[\text { ALMP/GDP] }}{\text { UNEM. }}$ & [ALMP/GDP] & $\frac{[\text { ALMP/GDP] }}{\text { UNEM. }}$ & $\frac{[\text { ALMP/GDP] }}{\text { UNEM. }}$ & [ALMP/GDP] & $\begin{array}{c}\text { [ALMP/GDP] } \\
\text { X RELIGION }\end{array}$ & $\begin{array}{c}\text { [ALMP/GDP] } \\
\text { X ETHIC }\end{array}$ \\
\hline \multirow[t]{2}{*}{ Dum_NMS } & $-7.655^{* *}$ & & & & & & & & & \\
\hline & $(2.817)$ & & & & & & & & & \\
\hline \multirow[t]{2}{*}{ Dum_Cont } & $-4.671 *$ & & & & & & & & & \\
\hline & $(2.590)$ & & & & & & & & & \\
\hline \multirow[t]{2}{*}{ Dum_Med } & $-8.373^{* *}$ & & & & & & & & & \\
\hline & $(3.367)$ & & & & & & & & & \\
\hline \multirow[t]{2}{*}{ Dum_Nord } & 3.862 & 3.860 & 0.125 & 1.912 & & & & & & \\
\hline & $(2.716)$ & $(2.759)$ & (3.432) & $(2.744)$ & & & & & & \\
\hline \multirow[t]{2}{*}{ Dum_FTR } & & $-5.560 * *$ & -1.419 & -0.766 & & & & & & \\
\hline & & $(2.586)$ & $(2.189)$ & $(1.935)$ & & & & & & \\
\hline \multirow[t]{2}{*}{ Dum_PoRo } & & $-16.491^{* * *}$ & $-15.836^{* * *}$ & $-16.073^{* * *}$ & & & & & & \\
\hline & & $(2.170)$ & $(1.767)$ & $(1.562)$ & & & & & & \\
\hline \multirow[t]{2}{*}{ Dum_CTE } & & $-5.433^{* *}$ & $-5.993^{*}$ & $-5.589 *$ & & & & & & \\
\hline & & $(2.519)$ & $(2.977)$ & $(2.868)$ & & & & & & \\
\hline \multirow[t]{2}{*}{ Dum_MEL } & & $-8.370^{* *}$ & $-6.523 * *$ & $-6.047^{* *}$ & & & & & & \\
\hline & & $(3.423)$ & $(2.531)$ & $(2.321)$ & & & & & & \\
\hline \multirow[t]{2}{*}{ Rigidity of Employment Index } & & & $-0.159 * * *$ & $-0.178^{* * *}$ & $-0.151^{*}$ & -0.125 & -0.041 & -0.067 & -0.065 & -0.044 \\
\hline & & & $(0.054)$ & $(0.045)$ & $(0.079)$ & $(0.081)$ & $(0.082)$ & $(0.082)$ & $(0.062)$ & $(0.069)$ \\
\hline \multirow[t]{2}{*}{ Tax Wedge } & & & -0.083 & -0.113 & $-0.362 * *$ & $-0.292^{*}$ & -0.238 & -0.236 & -0.265 & -0.232 \\
\hline & & & $(0.157)$ & $(0.154)$ & $(0.150)$ & $(0.149)$ & $(0.203)$ & $(0.217)$ & $(0.193)$ & $(0.206)$ \\
\hline \multirow[t]{2}{*}{ Union Density } & & & -0.015 & -0.029 & $0.106^{* *}$ & $0.096^{* *}$ & $0.115^{* *}$ & $0.136^{* * *}$ & 0.069 & 0.072 \\
\hline & & & $(0.069)$ & $(0.063)$ & $(0.044)$ & $(0.041)$ & $(0.047)$ & $(0.048)$ & $(0.056)$ & $(0.072)$ \\
\hline \multirow[t]{2}{*}{ Short Term Replacement Rate } & & & $0.188^{* * *}$ & $0.186^{* * *}$ & $0.149^{* *}$ & $0.123^{*}$ & 0.052 & 0.105 & 0.066 & 0.045 \\
\hline & & & $(0.066)$ & $(0.066)$ & $(0.067)$ & $(0.064)$ & $(0.093)$ & $(0.098)$ & $(0.082)$ & $(0.095)$ \\
\hline \multirow[t]{2}{*}{ ALMP } & & & 12.641 & 1.748 & 3.837 & $25.608^{* * *}$ & $18.703^{* * *}$ & 1.098 & $5.585^{* * *}$ & $16.185^{* * *}$ \\
\hline & & & (7.598) & $(1.253)$ & $(2.275)$ & $(8.807)$ & $(5.744)$ & $(1.322)$ & (1.683) & $(5.947)$ \\
\hline \multirow[t]{2}{*}{ ALMP X Culture } & & & & & & & & & $-8.863^{* * *}$ & $-42.569 * * *$ \\
\hline & & & & & & & & & (2.071) & (15.631) \\
\hline \multirow[t]{2}{*}{ Culture } & & & & & & & & & & -12.750 \\
\hline & & & & & & & & & & (19.560) \\
\hline \multirow[t]{2}{*}{ Change in Inflation (\% p.a.) } & 0.239 & 0.226 & 0.494 & 0.479 & $0.966^{*}$ & 0.808 & -0.211 & 0.061 & 0.066 & 0.193 \\
\hline & $(0.294)$ & $(0.378)$ & $(0.480)$ & $(0.501)$ & $(0.505)$ & $(0.486)$ & $(0.269)$ & $(0.252)$ & $(0.241)$ & $(0.282)$ \\
\hline Time Dummy & $\mathrm{Y}$ & $\mathrm{Y}$ & $\mathrm{Y}$ & $\mathrm{Y}$ & $\mathrm{Y}$ & $\mathrm{Y}$ & $\mathrm{Y}$ & $\mathrm{Y}$ & $\mathrm{Y}$ & $\mathrm{Y}$ \\
\hline
\end{tabular}




\begin{tabular}{|c|c|c|c|c|c|c|c|c|c|c|}
\hline & & & & & & & & & & \\
\hline Observations & 39 & 39 & 39 & 39 & 39 & 39 & 39 & 39 & 39 & 39 \\
\hline Adjusted R-squared or R2 overall & 0.52 & 0.58 & 0.72 & 0.70 & 0.47 & 0.55 & 0.54 & 0.46 & 0.62 & 0.59 \\
\hline RMSE & 4.12 & 3.89 & 3.19 & 3.25 & 4.33 & 4.01 & 1.26 & 1.34 & 1.21 & 1.39 \\
\hline Number of id & 23 & 23 & 23 & 23 & 23 & 23 & 23 & 23 & 23 & 23 \\
\hline
\end{tabular}

Robust standard errors in parentheses. ${ }^{*}$ significant at $10 \%$
Culture: = Religion (column 9), = Work-Ethic (column 10). 
Table 4. Dependent Variable: Employment Rate. Alternative Measures for Labor Market Expenditures

\begin{tabular}{|c|c|c|c|c|c|c|c|c|c|}
\hline & (1) & (2) & (3) & (4) & (5) & (6) & (7) & $(8)$ & (9) \\
\hline & \multicolumn{3}{|c|}{$\frac{[\text { LMP/GDP] }}{\text { UNEM. }}$} & \multicolumn{3}{|c|}{$\begin{array}{c}\text { [LMP/GDP] } \\
\text { X Religion }\end{array}$} & \multicolumn{3}{|c|}{$\begin{array}{c}\text { [LMP/GDP] } \\
\text { X Work-Ethic }\end{array}$} \\
\hline & ALMP & PLMP & TLMP & ALMP & PLMP & TLMP & ALMP & PLMP & TLMP \\
\hline \multirow[t]{2}{*}{ Rigidity of Employment Index } & -0.041 & -0.041 & -0.027 & -0.065 & -0.068 & -0.063 & -0.044 & -0.039 & -0.037 \\
\hline & $(0.082)$ & $(0.085)$ & $(0.087)$ & $(0.062)$ & $(0.071)$ & $(0.069)$ & $(0.069)$ & $(0.078)$ & $(0.080)$ \\
\hline \multirow[t]{2}{*}{ Tax Wedge } & -0.238 & -0.131 & -0.144 & -0.265 & -0.176 & -0.211 & -0.232 & -0.198 & -0.206 \\
\hline & $(0.203)$ & $(0.225)$ & $(0.217)$ & $(0.193)$ & $(0.214)$ & $(0.202)$ & $(0.206)$ & $(0.208)$ & $(0.209)$ \\
\hline \multirow[t]{2}{*}{ Union Density } & $0.115^{* *}$ & $0.105^{* *}$ & $0.094^{* *}$ & 0.069 & $0.088^{*}$ & 0.078 & 0.072 & 0.078 & 0.071 \\
\hline & $(0.047)$ & $(0.047)$ & $(0.046)$ & $(0.056)$ & $(0.054)$ & $(0.053)$ & $(0.072)$ & $(0.055)$ & $(0.060)$ \\
\hline \multirow[t]{2}{*}{ Short Term Replacement Rate } & 0.052 & 0.027 & 0.004 & 0.066 & 0.114 & 0.094 & 0.045 & 0.034 & 0.037 \\
\hline & $(0.093)$ & $(0.103)$ & $(0.101)$ & $(0.082)$ & $(0.102)$ & $(0.096)$ & $(0.095)$ & $(0.098)$ & $(0.099)$ \\
\hline \multirow[t]{2}{*}{ LMP } & $18.703^{* * *}$ & $15.757^{* *}$ & $11.654^{* * *}$ & $5.585^{* * *}$ & 2.041 & $1.693 * *$ & $16.185^{* * *}$ & 7.673 & $6.085^{*}$ \\
\hline & $(5.744)$ & $(6.438)$ & $(4.174)$ & $(1.683)$ & $(1.284)$ & $(0.764)$ & $(5.947)$ & (6.160) & (3.685) \\
\hline \multirow[t]{2}{*}{ LMP X Culture } & & & & $-8.863 * * *$ & $-3.916 * * *$ & $-2.725^{* * *}$ & $-42.569 * * *$ & -17.085 & -14.360 \\
\hline & & & & $(2.071)$ & (1.497) & $(0.816)$ & $(15.631)$ & (15.742) & $(9.364)$ \\
\hline \multirow[t]{2}{*}{ Culture } & & & & & & & -12.750 & -17.349 & -10.840 \\
\hline & & & & & & & $(19.560)$ & (23.163) & $(23.307)$ \\
\hline \multirow[t]{2}{*}{ Change in Inflation (\% p.a.) } & -0.211 & -0.163 & -0.296 & 0.066 & 0.022 & 0.032 & 0.193 & 0.201 & 0.145 \\
\hline & $(0.269)$ & $(0.226)$ & $(0.236)$ & $(0.241)$ & $(0.218)$ & $(0.221)$ & $(0.282)$ & $(0.274)$ & $(0.250)$ \\
\hline Time Dummy & $\mathrm{Y}$ & $\mathrm{Y}$ & $\mathrm{Y}$ & $\mathrm{Y}$ & $\mathrm{Y}$ & $\mathrm{Y}$ & $\mathrm{Y}$ & $\mathrm{Y}$ & $\mathrm{Y}$ \\
\hline Observations & 39 & 39 & 39 & 39 & 39 & 39 & 39 & 39 & 39 \\
\hline Number of id & 23 & 23 & 23 & 23 & 23 & 23 & 23 & 23 & 23 \\
\hline R2 overall & 0.54 & 0.54 & 0.55 & 0.62 & 0.57 & 0.60 & 0.59 & 0.62 & 0.61 \\
\hline RMSE & 1.26 & 1.12 & 1.11 & 1.21 & 1.27 & 1.31 & 1.39 & 1.45 & 1.43 \\
\hline
\end{tabular}

Robust standard errors in parentheses. ${ }^{*}$ significant at $10 \%$; ${ }^{* *}$ significant at $5 \%$; ${ }^{* * *}$ significant at $1 \%$. Culture: = Religion (columns 4-5-6), = Work-Ethic (columns $7-8-9$ ). 
Table 5. Dependent Variable: Participation Rate. Alternative Measures for Labor Market Expenditures

\begin{tabular}{|c|c|c|c|c|c|c|c|c|c|}
\hline & (1) & (2) & (3) & (4) & (5) & (6) & (7) & (8) & (9) \\
\hline & \multicolumn{3}{|c|}{$\frac{[L M P / G D P]}{\text { UNEM. }}$} & \multicolumn{3}{|c|}{$\begin{array}{l}\text { [LMP/GDP] } \\
\text { X Religion }\end{array}$} & \multicolumn{3}{|c|}{$\begin{array}{c}\text { [LMP/GDP] } \\
\text { X Work-Ethic }\end{array}$} \\
\hline & ALMP & PLMP & TLMP & ALMP & PLMP & TLMP & ALMP & PLMP & TLMP \\
\hline \multirow[t]{2}{*}{ Rigidity of Employment Index } & -0.058 & -0.068 & -0.059 & -0.064 & -0.066 & -0.053 & -0.055 & -0.047 & -0.042 \\
\hline & $(0.071)$ & $(0.068)$ & $(0.071)$ & $(0.055)$ & $(0.063)$ & $(0.059)$ & $(0.063)$ & $(0.071)$ & $(0.073)$ \\
\hline \multirow[t]{2}{*}{ Tax Wedge } & -0.076 & -0.004 & -0.012 & -0.147 & 0.012 & -0.085 & -0.095 & -0.025 & -0.066 \\
\hline & $(0.185)$ & $(0.201)$ & $(0.194)$ & $(0.167)$ & $(0.201)$ & $(0.175)$ & $(0.212)$ & $(0.218)$ & $(0.211)$ \\
\hline \multirow[t]{2}{*}{ Union Density } & $0.091^{* *}$ & $0.087^{* *}$ & $0.080^{* *}$ & 0.055 & 0.046 & 0.044 & 0.067 & 0.065 & 0.060 \\
\hline & $(0.041)$ & $(0.041)$ & $(0.041)$ & $(0.046)$ & $(0.047)$ & $(0.045)$ & $(0.065)$ & $(0.052)$ & $(0.054)$ \\
\hline \multirow[t]{2}{*}{ Short Term Replacement Rate } & 0.047 & 0.042 & 0.028 & 0.047 & 0.062 & 0.048 & 0.041 & 0.033 & 0.039 \\
\hline & $(0.094)$ & $(0.097)$ & $(0.099)$ & $(0.073)$ & $(0.092)$ & $(0.077)$ & $\begin{array}{l}(0.101) \\
\end{array}$ & $(0.115)$ & $(0.103)$ \\
\hline \multirow[t]{2}{*}{ LMP } & $10.719 * *$ & $7.643^{*}$ & $5.976^{*}$ & $4.661^{* * *}$ & $2.612^{* * *}$ & $1.992^{* * *}$ & $13.732^{* * *}$ & 6.643 & $6.147^{*}$ \\
\hline & (5.192) & (4.291) & (3.079) & $(1.584)$ & $(1.012)$ & $(0.556)$ & $(4.589)$ & (5.906) & (3.352) \\
\hline \multirow[t]{2}{*}{ LMP X Culture } & & & & $-6.406^{* * *}$ & $-3.677^{* * *}$ & $-2.400^{* * *}$ & $-34.774^{* * *}$ & -13.759 & -13.949 \\
\hline & & & & (1.659) & (1.158) & $(0.614)$ & $(11.652)$ & (15.672) & $(8.740)$ \\
\hline \multirow[t]{2}{*}{ Culture } & & & & & & & 3.004 & -1.083 & 8.122 \\
\hline & & & & & & & $(16.150)$ & (22.903) & (20.778) \\
\hline \multirow{2}{*}{ Change in Inflation (\% p.a.) } & -0.329 & -0.263 & -0.341 & -0.144 & -0.259 & -0.220 & -0.196 & -0.204 & -0.235 \\
\hline & $(0.220)$ & (0.193) & $(0.210)$ & $(0.236)$ & $(0.165)$ & (0.181) & $(0.198)$ & (0.166) & $(0.158)$ \\
\hline Time Dummy & $\mathrm{Y}$ & $\mathrm{Y}$ & $\mathrm{Y}$ & $\mathrm{Y}$ & $\mathrm{Y}$ & $\mathrm{Y}$ & $\mathrm{Y}$ & $\mathrm{Y}$ & $\mathrm{Y}$ \\
\hline Observations & 39 & 39 & 39 & 39 & 39 & 39 & 39 & 39 & 39 \\
\hline Number of id & 23 & 23 & 23 & 23 & 23 & 23 & 23 & 23 & 23 \\
\hline R2 overall & 0.45 & 0.43 & 0.45 & 0.65 & 0.57 & 0.63 & 0.50 & 0.49 & 0.51 \\
\hline RMSE & 0.92 & 0.89 & 0.88 & 0.95 & 0.86 & 0.95 & 0.93 & 0.96 & 0.98 \\
\hline
\end{tabular}

Robust standard errors in parentheses. ${ }^{*}$ significant at $10 \%$; ${ }^{* *}$ significant at $5 \%$; ${ }^{* * *}$ significant at $1 \%$. Culture: = Religion (columns 4-5-6), = Work-Ethic (columns $7-8-9$ ). 
Table A1. Variables used in the regressions

\begin{tabular}{|c|c|}
\hline VARIABLE & SOURCE / DEFINITION \\
\hline Employment rate & Em011 Eurostat \\
\hline Unemployment rate & Em071 Eurostat \\
\hline Participation rate & (Employment Rate)*[1/(1-Unemployment rate) $]$ \\
\hline Inflation rate & Em040 Eurostat \\
\hline $\begin{array}{l}\text { At risk of poverty rate after Social } \\
\text { Transfers }\end{array}$ & Tsisc030 Eurostat \\
\hline Change in Inflation (\% p.a.) & (Inflation end of the period) - (Inflation at the beginning of the period) \\
\hline Dum_Nord & Nordic. $\quad=1$ for: Denmark, Finland, Netherlands and Sweden \\
\hline Dum_NMS & New Member States. = 1 for: Bulgaria, Cyprus, Czech Republic, Estonia, Hungary, Latvia, Lithuania, Malta, Poland, Romania, Slovakia and Slovenia \\
\hline Dum_Cont & = 1 for: Austria, Belgium, France, Germany and Luxembourg \\
\hline Dum_Med & Mediterranean $\quad=1$ for: Greece, Italy, Portugal and Spain \\
\hline Dum_FTR & Fast Transition $\quad=1$ for: Bulgaria, Estonia, Latvia, Lithuania and Slovenia \\
\hline Dum_PoRo & $=1$ for: Poland and Romania \\
\hline Dum_CTE & Continental Enlarged = 1 for: Austria, Belgium, Czech Republic, France, Germany, Hungary, Luxembourg and Slovakia \\
\hline Dum_MEE & Mediterranean Enlarg = 1 for: Cyprus, Greece, Italy, Malta, Portugal and Spain \\
\hline Rigidity of Employment Index & Doing Business database, World Bank. Available since 2003. For 1999-2002 we use the value of 2003 in the regressions. \\
\hline Tax Wedge & Em045 Eurostat, Implicit tax rate on labor. \\
\hline Union Density & Registered trade union membership, \%. Source: Visser, “Union membership statistics in 24 countries”, Monthly Labor Review, January 2006. \\
\hline Short Term Replacement Rate & $\begin{array}{l}\text { Net value of replacement benefits in the initial phase of unemployment relative to average wage, single with no children. } 2001 \text { for } 1999,2004 \text { for } 2006 . \\
\text { (OECD). }\end{array}$ \\
\hline Employment Protection Laws & Overall EPL strictness version 2, available for 18 countries. Source: OECD. \\
\hline
\end{tabular}




\begin{tabular}{|l|l|}
\hline Product Market Regulation & $\begin{array}{l}\text { Source: OECD Indicators of Product Market Regulation for 1998 and 2003. (See: Conway, P., V. Janod, and G. Nicoletti (2005), "Product Market Regulation } \\
\text { in OECD Countries, 1998 to 2003", OECD Economics Department Working Paper, No 419). Available for 18 EU countries. }\end{array}$ \\
\hline Labor Market Expenditures $2-7$ & $=$ Labor Market Polices, Active policies, items 2-7 Eurostat. \\
\hline Labor Market Expenditures $1-9$ & $=$ Labor Market Polices, Overall Expenditures policies, items 1-9 Eurostat \\
\hline Labor Market Expenditures $8-9$ & $=$ Labor Market Polices, Passive Labor Market Expenditures 8- 9 Eurostat \\
\hline Work-Ethic & $=\%$ of respondents who strongly agree with "people should not have to work if they do not want to", i.e. high value associated with low work-ethic. \\
\hline Religion & $=1$ for prevailing (>50\%) Catholic or Orthodox affiliation \\
\hline "var1" X"var2" & interaction term between "var1" and "var2" \\
\hline Robust standard errors in parentheses clustered at the level of the country. * *significant at 10\%; ** significant at 5\%; *** significant at 1\%
\end{tabular}


Table A2. Dependent Variable: Employment Rate. Enlarged sample (25 countries)

\begin{tabular}{|c|c|c|c|c|c|c|c|c|c|}
\hline & (1) & (2) & (3) & (4) & (5) & (6) & (7) & (8) & (9) \\
\hline & \multicolumn{3}{|c|}{$\frac{[\text { LMP/GDP] }}{\text { UNEM. }}$} & \multicolumn{3}{|c|}{$\begin{array}{c}\text { [LMP/GDP] } \\
\text { X Religion }\end{array}$} & \multicolumn{3}{|c|}{$\begin{array}{c}{[\text { LMP/GDP] }} \\
\text { X Work-Ethic }\end{array}$} \\
\hline & ALMP & PLMP & TLMP & ALMP & PLMP & TLMP & ALMP & PLMP & TLMP \\
\hline Rigidity of Employment Index & $(0.073)$ & $(0.075)$ & $(0.075)$ & $(0.061)$ & $(0.071)$ & $(0.067)$ & $(0.059)$ & $(0.072)$ & $(0.071)$ \\
\hline \multirow[t]{2}{*}{ Tax Wedge } & -0.099 & 0.012 & -0.041 & -0.209 & -0.070 & -0.137 & -0.114 & -0.045 & -0.078 \\
\hline & $(0.177)$ & $(0.200)$ & $(0.183)$ & $(0.157)$ & $(0.205)$ & $(0.181)$ & $(0.180)$ & $(0.192)$ & $(0.187)$ \\
\hline \multirow[t]{2}{*}{ LMP X Culture } & & & & $-10.483^{* * *}$ & $-4.316^{* * *}$ & $-3.162^{* * *}$ & $-47.399 * * *$ & -15.373 & $-14.796 *$ \\
\hline & & & & (1.911) & (1.425) & $(0.806)$ & $(15.283)$ & $\begin{array}{l}(13.258) \\
\end{array}$ & (8.471) \\
\hline \multirow[t]{2}{*}{ Culture } & & & & & & & $-20.247^{*}$ & $-25.803^{*}$ & -18.345 \\
\hline & & & & & & & (11.453) & (15.119) & (14.906) \\
\hline \multirow{2}{*}{ Change in Inflation (\% p.a.) } & $-0.413^{* *}$ & $-0.285^{*}$ & $-0.381^{* *}$ & -0.124 & -0.177 & -0.195 & -0.081 & -0.114 & -0.137 \\
\hline & $(0.207)$ & $(0.165)$ & $(0.167)$ & $(0.174)$ & $(0.169)$ & $(0.167)$ & $(0.161)$ & $(0.159)$ & $(0.152)$ \\
\hline Time Dummy & $\mathrm{Y}$ & $\mathrm{Y}$ & $\mathrm{Y}$ & $\mathrm{Y}$ & $\mathrm{Y}$ & $\mathrm{Y}$ & $\mathrm{Y}$ & $\mathrm{Y}$ & $\mathrm{Y}$ \\
\hline RMSE & 1.22 & 1.07 & 1.05 & 1.23 & 1.26 & 1.28 & 1.23 & 1.27 & 1.26 \\
\hline
\end{tabular}

Robust standard errors in parentheses. * Significant at $10 \%$; ${ }^{* *}$ significant at $5 \%$; *** significant at $1 \%$. Culture: = Religion (columns 4-5-6), = Work-Ethic (columns $7-8-9$ ). 
Table A3. Dependent Variable: Employment Rate. Alternative Measure of Employment Protection Legislation (OECD) and Product Market Regulation

\begin{tabular}{|c|c|c|c|c|c|c|c|c|c|}
\hline & (1) & $(2)$ & (3) & (4) & (5) & (6) & (7) & $(8)$ & (9) \\
\hline & \multicolumn{3}{|c|}{$\frac{[\mathrm{LMP} / \mathrm{GDP}]}{\text { UNEM. }}$} & \multicolumn{3}{|c|}{$\begin{array}{c}\text { [LMP/GDP] } \\
\mathrm{X} \text { Religion }\end{array}$} & \multicolumn{3}{|c|}{$\begin{array}{c}{[\text { [LMP/GDP] }} \\
\text { X Work-Ethic }\end{array}$} \\
\hline & ALMP & PLMP & TLMP & ALMP & PLMP & TLMP & ALMP & PLMP & TLMP \\
\hline \multirow[t]{2}{*}{ EPL } & 0.312 & -0.082 & 0.202 & 0.513 & 0.195 & 0.370 & -0.083 & -1.228 & -0.891 \\
\hline & $(1.981)$ & $(1.841)$ & $(1.848)$ & $(2.084)$ & $(1.977)$ & $(2.017)$ & $(2.189)$ & $(1.989)$ & $(2.053)$ \\
\hline \multirow[t]{2}{*}{ Tax Wedge } & -0.214 & -0.174 & -0.170 & -0.237 & -0.175 & -0.178 & -0.204 & -0.166 & -0.172 \\
\hline & $(0.185)$ & $(0.195)$ & $(0.195)$ & $(0.189)$ & $(0.183)$ & $(0.189)$ & $(0.202)$ & $(0.178)$ & $(0.180)$ \\
\hline \multirow[t]{2}{*}{ Union Density } & $0.108^{* * *}$ & $0.110^{* * *}$ & $0.101^{* * *}$ & 0.060 & 0.059 & 0.043 & 0.071 & 0.058 & 0.046 \\
\hline & $(0.040)$ & $(0.039)$ & $(0.038)$ & $(0.048)$ & $(0.055)$ & $(0.057)$ & $(0.059)$ & $(0.049)$ & $(0.051)$ \\
\hline \multirow[t]{2}{*}{ Short Term Replacement Rate } & 0.054 & 0.048 & 0.025 & 0.022 & 0.065 & 0.030 & 0.045 & 0.096 & 0.065 \\
\hline & $(0.123)$ & $(0.121)$ & $(0.119)$ & $(0.128)$ & $(0.118)$ & $(0.122)$ & $(0.141)$ & $(0.104)$ & $(0.110)$ \\
\hline \multirow[t]{2}{*}{ Product Market Regulation } & $-4.172^{*}$ & -3.665 & -3.396 & -4.365 & $-5.484^{* *}$ & $-5.357^{* *}$ & -3.827 & -4.061 & -4.166 \\
\hline & $(2.397)$ & $(2.247)$ & $(2.163)$ & $(2.763)$ & $(2.535)$ & $(2.556)$ & $(2.635)$ & (3.264) & (3.011) \\
\hline \multirow[t]{2}{*}{ LMP } & $19.221 * *$ & $14.971 * *$ & $11.482^{* * *}$ & $5.574 * * *$ & $2.710^{*}$ & $2.281^{* *}$ & 13.114* & $9.230^{*}$ & 6.028 \\
\hline & $(7.695)$ & $(6.642)$ & $(4.377)$ & $(2.099)$ & $(1.638)$ & $(1.070)$ & $(6.983)$ & $(5.610)$ & (3.687) \\
\hline \multirow[t]{2}{*}{ LMP X Culture } & & & & $-7.011^{* *}$ & $-3.251^{*}$ & $-2.163^{* *}$ & $-31.036^{*}$ & -20.367 & -12.422 \\
\hline & & & & $(2.877)$ & $(1.757)$ & $(1.064)$ & $(18.652)$ & (14.914) & $(9.460)$ \\
\hline \multirow[t]{2}{*}{ Culture } & & & & & & & -4.301 & 0.370 & 1.110 \\
\hline & & & & & & & $(17.292)$ & $(20.548)$ & $\begin{array}{ll}(19.372) \\
\end{array}$ \\
\hline \multirow[t]{2}{*}{ Change in Inflation (\% p.a.) } & -0.506 & -0.382 & -0.491 & -0.311 & -0.305 & -0.390 & -0.285 & 0.132 & -0.030 \\
\hline & $(0.492)$ & $(0.411)$ & $(0.385)$ & $(0.501)$ & $(0.524)$ & $(0.469)$ & $(0.411)$ & $(0.652)$ & $(0.537)$ \\
\hline Time Dummy & $\mathrm{Y}$ & $\mathrm{Y}$ & $\mathrm{Y}$ & $\mathrm{Y}$ & $\mathrm{Y}$ & $\mathrm{Y}$ & $\mathrm{Y}$ & $\mathrm{Y}$ & $\mathrm{Y}$ \\
\hline Observations & 31 & 31 & 31 & 31 & 31 & 31 & 31 & 31 & 31 \\
\hline Number of id & 18 & 18 & 18 & 18 & 18 & 18 & 18 & 18 & 18 \\
\hline R2 overall & 0.64 & 0.67 & 0.68 & 0.69 & 0.69 & 0.70 & 0.64 & 0.70 & 0.70 \\
\hline RMSE & 1.60 & 1.49 & 1.40 & 1.50 & 1.75 & 1.66 & 1.56 & 2.19 & 2.05 \\
\hline
\end{tabular}

Robust standard errors in parentheses * significant at $10 \%$; ** significant at $5 \%$; ${ }^{* * *}$ significant at $1 \%$. Culture: = Religion (columns 4-5-6), = Work-Ethic (columns $7-8-9$ ). 
Figure 1. Employment rates in the EU-27, 1999 - 2006
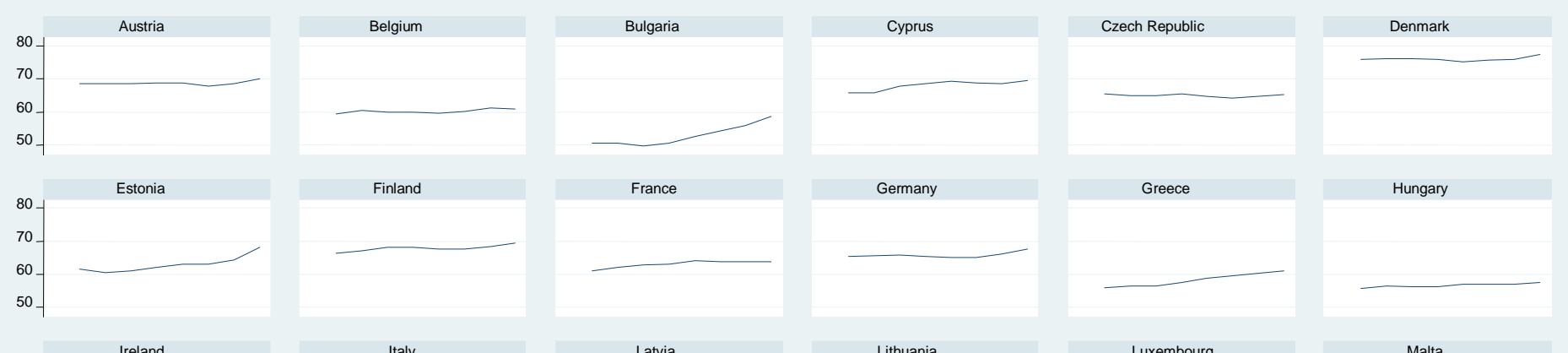

Hungary
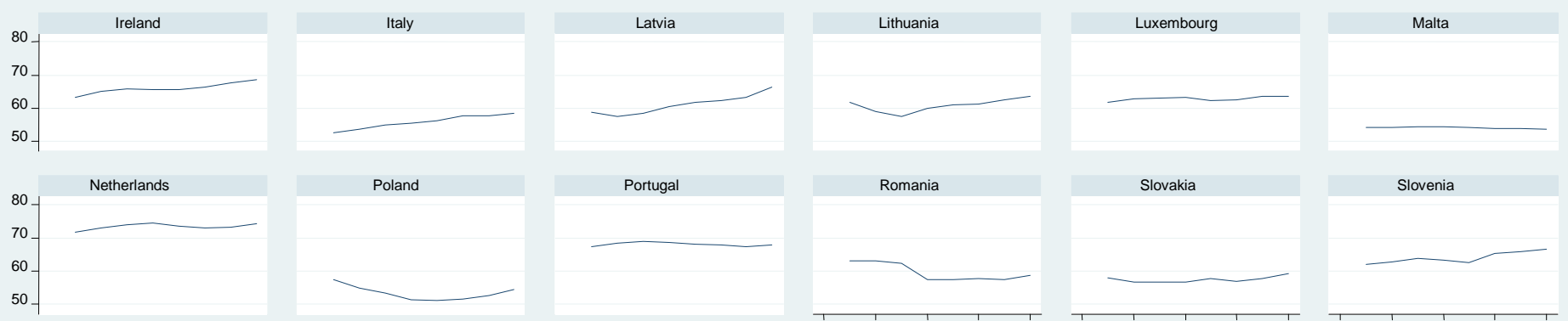

Portugal

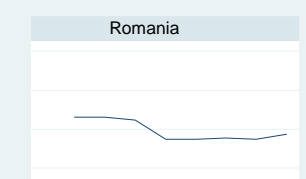

Slovakia

Slovenia $\begin{array}{lllllllllllllll}1998 & 2000 & 2002 & 2004 & 2006 & 1998 & 2000 & 2002 & 2004 & 2006 & 1998 & 2000 & 2002 & 2004 & 2006\end{array}$

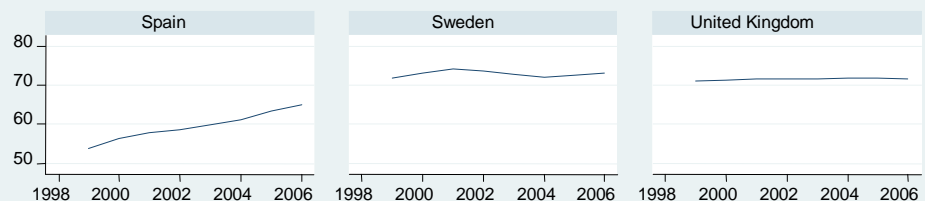


Fig. 2: Employment Rate vs. Risk of Poverty

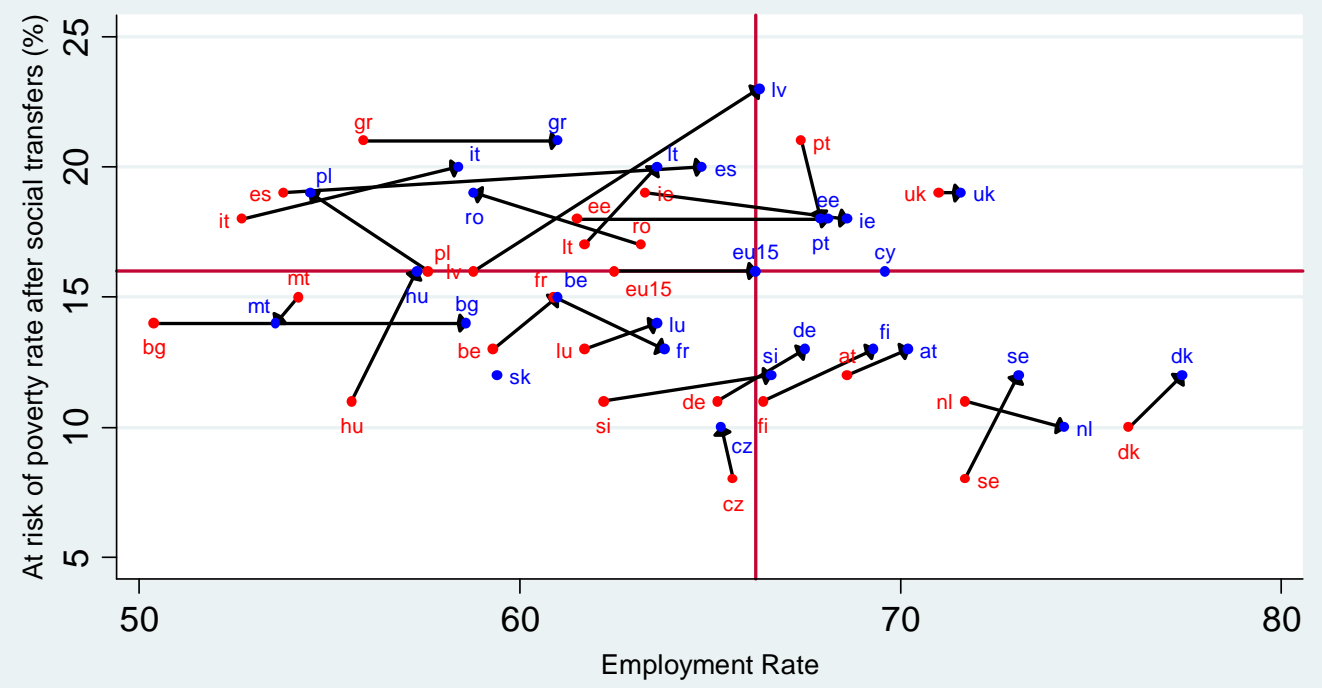

\section{$\longrightarrow$ 1999-2006 $\bullet 1999 \cdot 2006$}

Poverty data not available for Cyprus and Slovakia in 1999.

Poverty data for Bulgaria, Estonia, Latvia, Lithuania, Hungary, Malta, Poland and Slovenia in 1999 replaced with 2000.

Fig. 3. Traditional Geographical Dummies (Tab.3, col. 1)

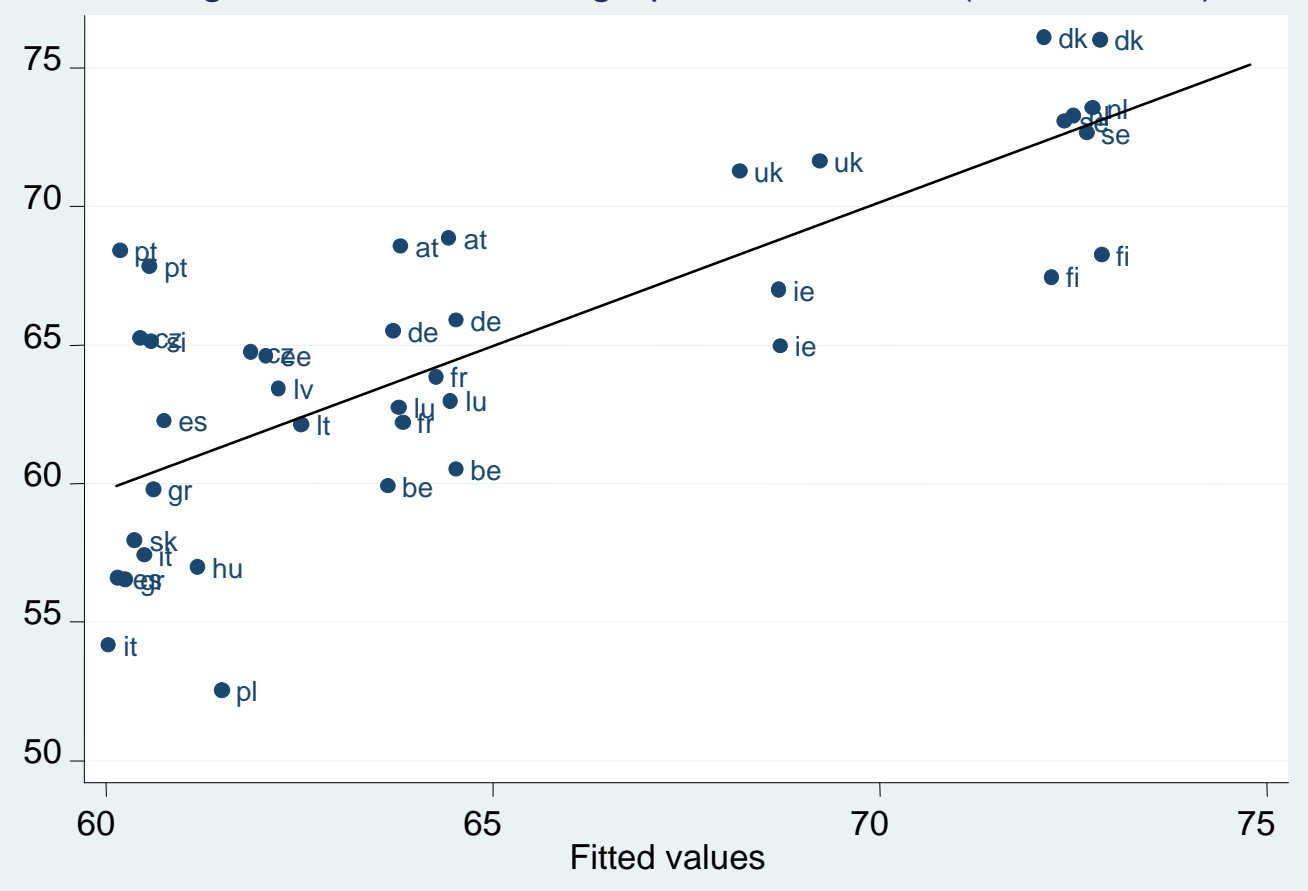


Fig. 4: New Geographical Dummies (Tab.3, col. 2)

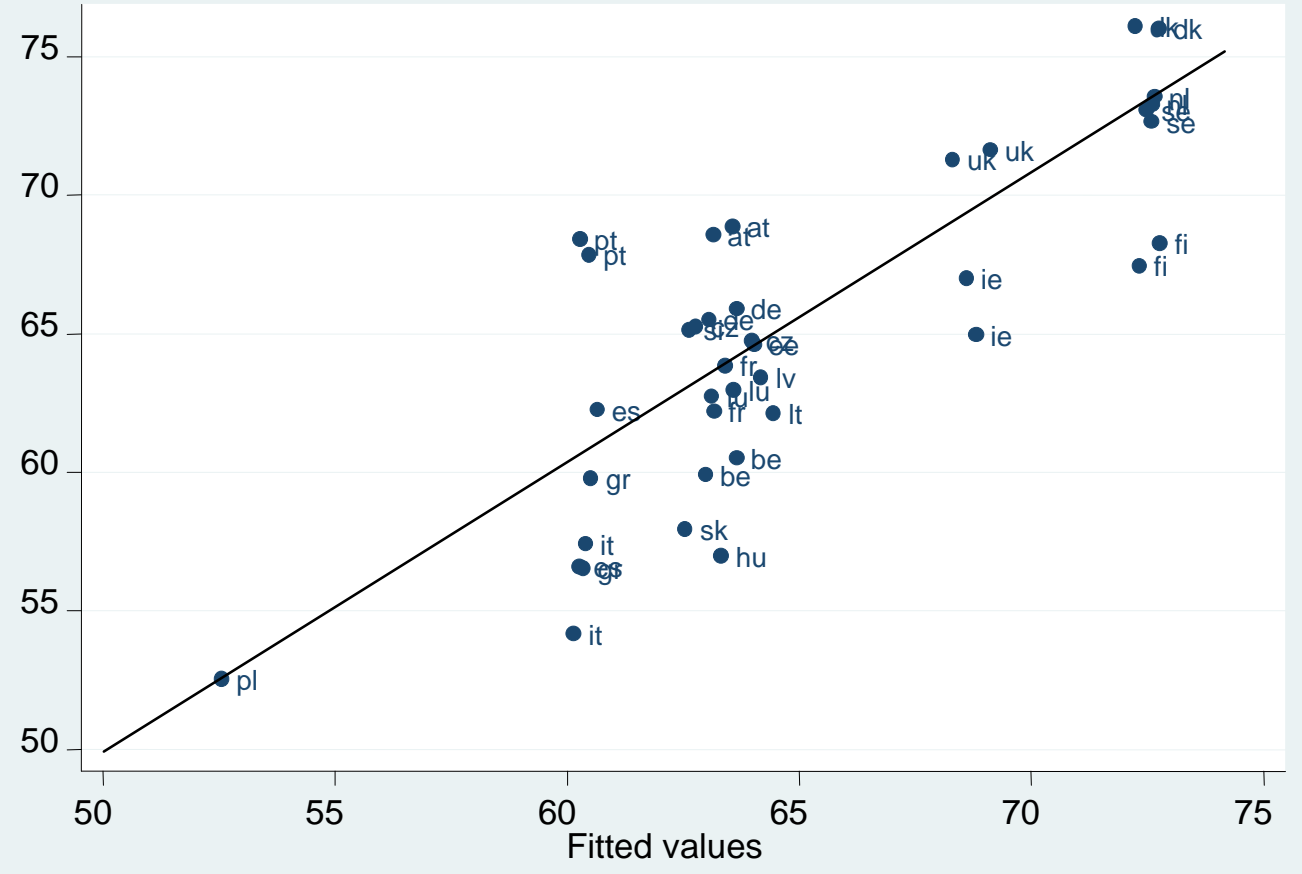

Fig. 5: RE Model with Work Ethic (Tab.3, col. 10)

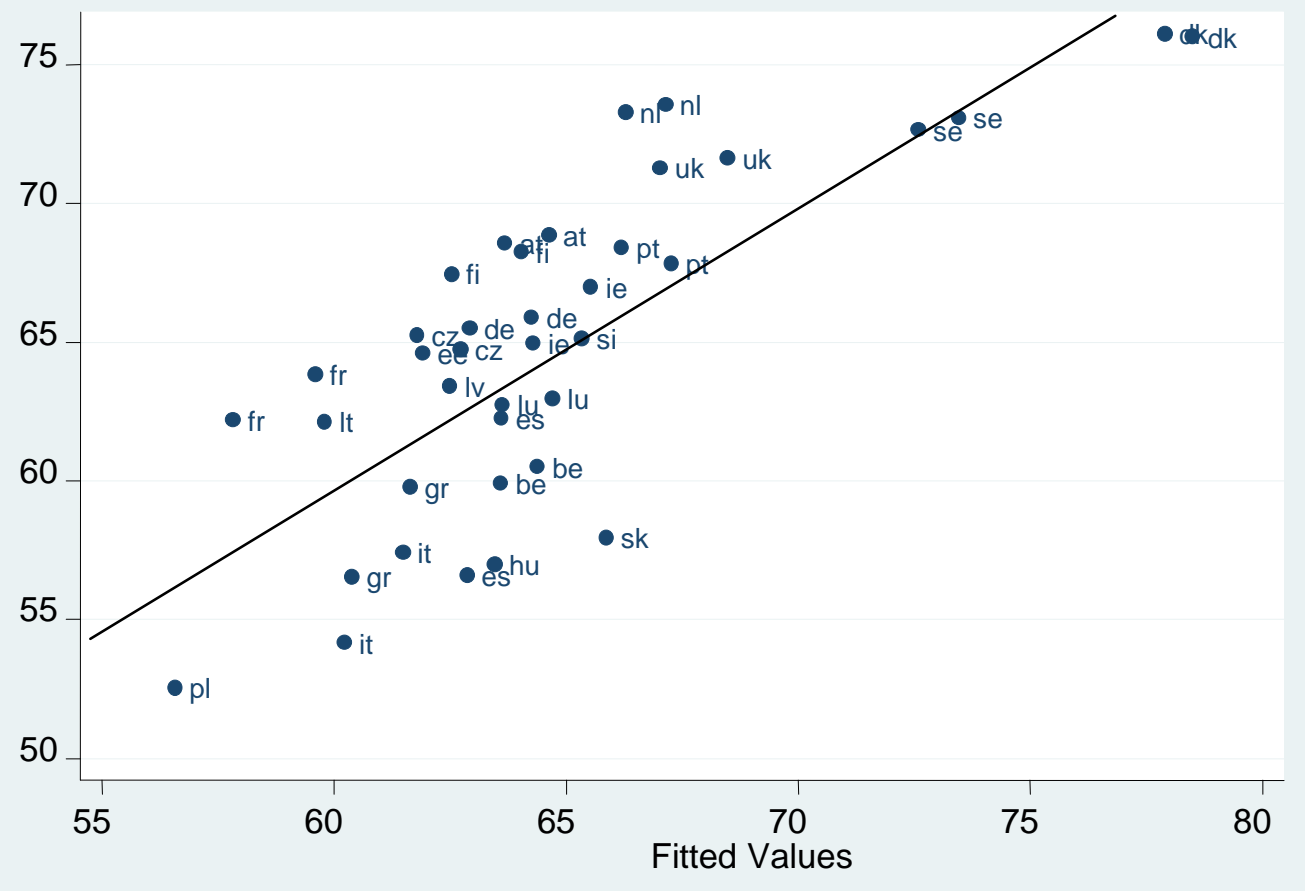

